\title{
THERMAL PROPERTIES OF A NEW PAVEMENT MATERIAL FOR USING IN ROAD CONSTRUCTION
}

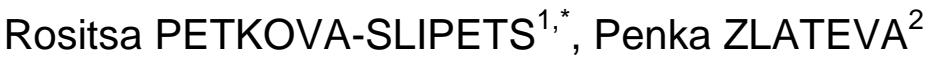 \\ ${ }^{1}$ Department of Civil Engineering, Faculty of Architecture, Varna Free University "Chernorizets \\ Hrabar", Resort Chaika, 9007 Bulgaria. \\ 2 Department of Thermal Engineering, Shipbuilding Faculty, Technical University of Varna, Studentska \\ Str., 9010 Varna, Bulgaria. \\ corresponding author: rositsa.petkova@vfu.bg.
}

\section{Abstract}

The paper presents the results from a study of the thermo-physical properties of a new synthetic acrylic polymer used as material in road construction and as concrete on its basis. For the purposes of the study, the Modified Transient Plane Source Method (MTPS) was used. Data on the following thermal characteristics were obtained: thermal conductivity coefficient, thermal effusion, thermal diffusion and specific thermal capacity. A comparative analysis was made with the analogous indicators of conventional petroleum bitumen and asphalt concrete. The results of the study can be used for a more precise calculation and prognosis of temperature deformations and thermal stresses, as well as the crack propensity at low temperatures in asphalt concretes.
\end{abstract}

\author{
Keywords: \\ Thermal properties; \\ Pavement materials; \\ Acrylic polymer; \\ Modified transient plane source \\ method.
}

\section{Introduction}

Materials used for road paving in road constructions are exploited under some of the toughest conditions: highly dynamic loading combined with direct exposure to temperature, water and various corrosive agents. Road surfaces possess the most heat-absorbing color - black, and cover large areas in and between urban areas [1 - 4].

From a thermo-physical point of view, the road surface, or the materials from which it is built respectively, performs unidirectional non-stationary heat exchange through conduction, convection and radiation, both between the layers and the environment (Fig. 1) [5 - 8]. Heat exchange processes result in a change in the mechanical behavior of the road paving materials - they get deformed in temperature amplitudes, which also generate thermal stresses (Fig. 2) [7].

Calculation of thermal stresses in asphalt concretes is hampered by the fact that they behave as viscoelastic materials. In such cases, according to Marasteanu et al. [7, 8], indicative is the temperature gradient:

$\rho \cdot C \cdot \frac{\partial T}{\partial t}=k \cdot \frac{\partial^{2} T}{\partial x^{2}}$

where: $k$ - thermal conductivity coefficient, W/m.K; $T$ - temperature, $\mathrm{K} ; t-$ time, $\mathrm{s} ; C$ - specific heat capacity, J/kg.K; $\rho$ - density, $\mathrm{kg} / \mathrm{m}^{3}$.

As a result of the simulations conducted, based on the modelling of the heat processes, according to equation (1), and after setting the respective boundary, initial, geometric and physical conditions, it was assumed that the thermal stresses are significantly lower for asphalt materials with a higher thermal conductivity coefficient [8]. This is the base of constant demand for new materials in road construction and of the orientation to synthetic polymers $[14,15]$. 


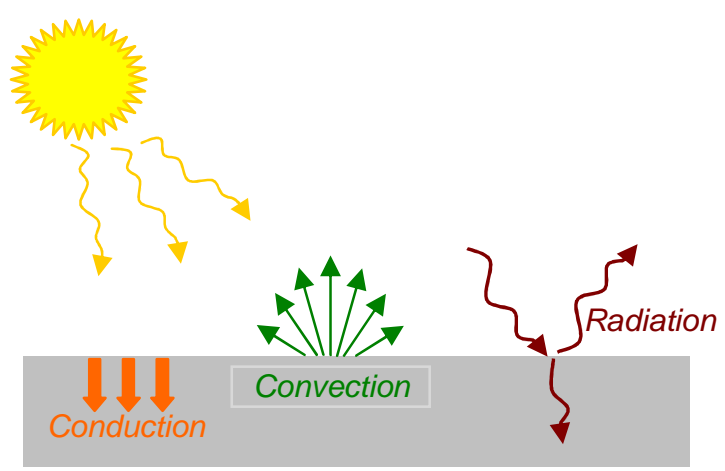

Fig. 1: Schematic representation of the heat-transfer processes in road structure.
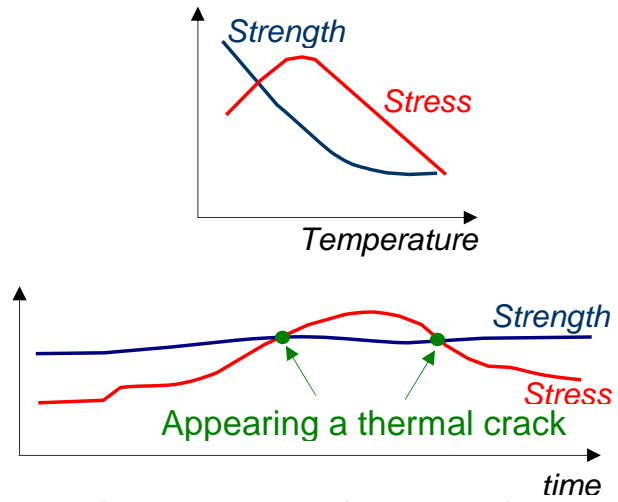

Fig. 2: Schematic representation of the conditions for cracks formations in asphalt concretes [7].

The thermo-physical properties of asphalt concretes have been the subject of research for many years by many authors (Table 1). However, there are no uniform values of the thermo-physical indicators of the asphalt-concrete materials because they are highly dependent on the composition of the mixture, the density and the temperature $[7,9]$. Precise determination is recommended of the thermo-physical properties for a particular asphalt composition. Despite the many years of research, there are still no uniform standards to regulate the test methods and conditions for determining the thermo-physical properties of asphalt concretes.

Table 1: Thermo-physical characteristics of the asphalt concretes according to different sources.

\begin{tabular}{|l|c|c|c|}
\hline \multicolumn{1}{|c|}{ Source } & $\boldsymbol{k}, \mathbf{W} / \mathbf{m} / \mathbf{K}$ & $\boldsymbol{\rho} \cdot \boldsymbol{C p} \cdot \mathbf{1 0}^{\mathbf{6}}, \mathbf{J} / \mathbf{m}^{\mathbf{3}} \cdot \mathbf{K}$ & $\boldsymbol{\alpha} \cdot \mathbf{1 0}^{-7}, \mathbf{m}^{\mathbf{2}} / \mathbf{s}$ \\
\hline Kersten (1949) [9] & 1.49 & - & - \\
\hline Corlew and Dickson (1968) [9] & 1.21 & 2.05 & 5.9 \\
\hline Jordan and Thomas (1976) [9] & $0.8-1.06$ & $2-2.16$ & $3.7-5.3$ \\
\hline Turner and Malboy (1981) [9] & 0.76 & - & $5-13$ \\
\hline Chadbourn (1996) [9] & $0.6-2.5$ & $1.2-1.9$ & - \\
\hline CLPM at IAP (ЦЛПМ при ИАП) (2003) [10] & $0.55-1.30$ & - & $4.42-6.39$ \\
\hline Luka and Mrawira (2005) [11] & $1.45-1.81$ & $2.69-3.29$ & $3.8-6.1$ \\
\hline Mrawira and Luka (2006) [12] & $1.38-2.11$ & $2.31-4.8$ & - \\
\hline Cote (2013) [13] & $1.19-1.49$ & - & \\
\hline
\end{tabular}

$k$ - thermal conductivity coefficient - a measure of the material's capability to conduct heat; $c_{p}$ - specific heat capacity - a measure of the material's capability to accumulate thermal energy [5]; $\alpha$-thermal diffusion - a measure of the velocity of a heat dissipation from the material to the environment $[5,9]$.

With the advancement of measuring technologies, the Modified Transient Plane Source Method (MTPS) has been developed by Mathis Instruments Ltd. in 2004 [16]. It is based on Gustafsson's [17] proposed Transient Plane Source (TPS) method. This method has several main advantages: - it allows unilateral in-situ measurement or in laboratory conditions; - the size and shape of the tested 
materials is irrelevant; - short-term testing, etc. The results obtained from measurements based on MTPS show a good correlation with the values obtained by the other methods [18, 19].

The aim of the present study was to determine the basic thermo-physical properties of a new synthetic acrylic polymer material as well as concrete based on this polymer. The thermo-technical characteristics were determined by applying the MTPS Method. A comparative analysis was carried out with the characteristics of petroleum bitumen and asphalt-concrete. The thermo-physical properties, which were determined, are: thermal conductivity coefficient, thermal diffusion, specific thermal capacity and thermal effusion. The data thus obtained can be used to determine the shortterm thermal conductivity in each asphalt layer as well as to model the time-temperature dependence in asphalt concretes. Specific for this study is the determination of the thermal effusion $e$, which characterizes the ability of the material to exchange heat with the surrounding environment.

The compositions of both tested concretes were the same, only the binder underwent modifications. The test results can be used for more accurate calculations and predictions of temperature deformations and thermal stresses, or the crack propensity at low temperatures, respectively.

\section{Materials and methods}

\subsection{Materials}

Subject to the study were four samples (Fig. 3, Table 2), made from the following materials:

- sample 1-a new generation synthetic thermoplastic acrylate polymer for hot mix asphalts with rheological properties analogous to the bitumen [14, 15];

- sample 2 - dense asphalt concrete with a thermoplastic acrylate polymer as a binder;

- sample 3 - viscous petroleum bitumen for road pavements;

- sample 4 -dense asphalt concrete with a viscous petroleum bitumen as a binder.

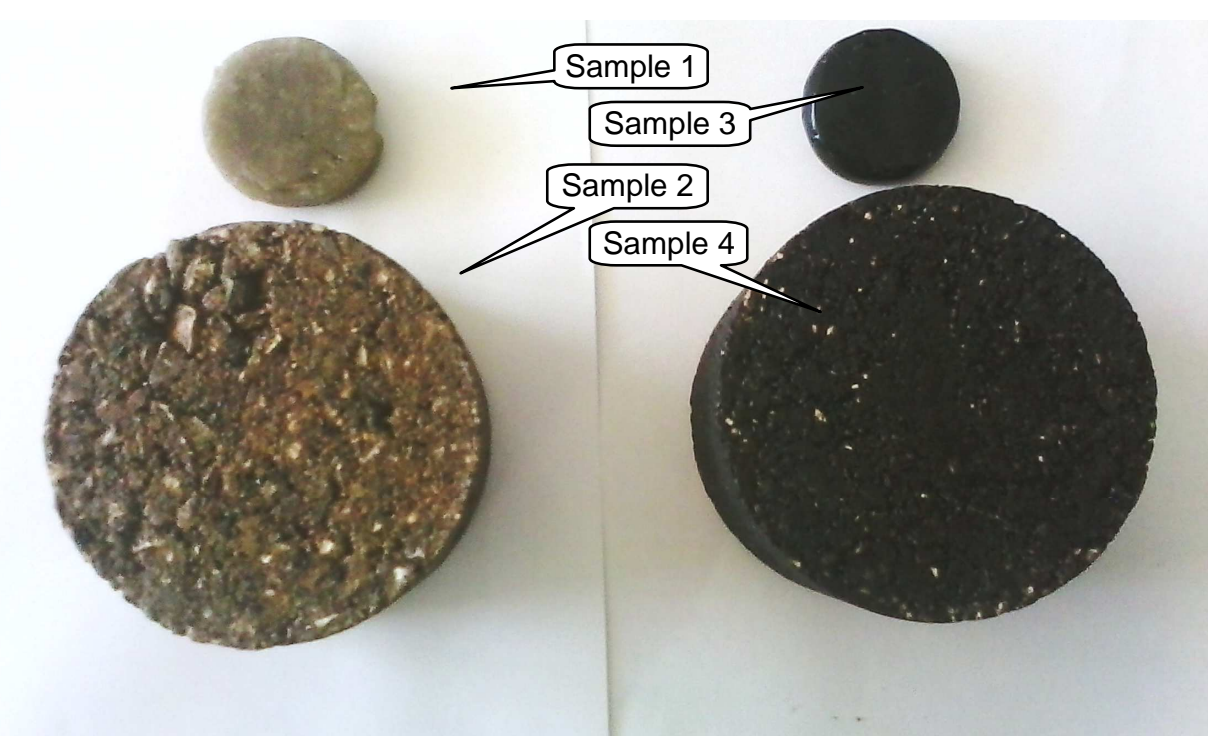

Fig. 3: General view of the testing materials.

All specimens were with cylindrical shape. Sample 1 and sample 3 were with a diameter of $\phi 45$ $\mathrm{mm}$ and with a height of $10 \mathrm{~mm}$. Sample 2 and sample 4 were prepared by the same recipe but with a different binder. They are core specimens (with a diameter of $\phi 60 \mathrm{~mm}$ and a height of $60 \mathrm{~mm}$ ) of the asphalt mixtures, designed and used into real objects. 
Table 2: Characteristics of testing materials.

\begin{tabular}{|c|c|c|c|c|}
\hline Study material & $\begin{array}{l}\text { Density } \rho \\
\mathrm{kg} / \mathrm{m}^{3}\end{array}$ & $\begin{array}{c}\text { Penetration } \\
\text { at } 25^{\circ} \mathrm{C}^{1)} \\
0.1 \mathrm{~mm}\end{array}$ & $\begin{array}{c}\text { Softening } \\
\text { point }^{2}{ }^{\circ} \mathrm{C}\end{array}$ & $\begin{array}{c}\text { Air voids } \\
\text { content }^{3)} \\
\%\end{array}$ \\
\hline Synthetic thermoplastic acrylate polymer (sample 1) & 991 & 46 & 66.6 & - \\
\hline $\begin{array}{l}\text { Dense asphalt concrete with a thermoplastic acrylate } \\
\text { polymer (sample 2) }\end{array}$ & 2284 & - & - & 3 \\
\hline Viscous petroleum bitumen (sample 3) & 936 & 60 & 53 & - \\
\hline $\begin{array}{l}\text { Dense asphalt concrete with a viscous petroleum } \\
\text { bitumen (sample 4) }\end{array}$ & 2217 & - & - & 3 \\
\hline
\end{tabular}

1)according БДС EN 1426:2015; ' 2)according БДС EN 1427:2015; ;)according БДС EN 12697-8:2003.

\subsection{Experimental test method}

For the purposes of this study, a TCi thermal conductivity analyzer was used (Fig. 4). The effusion $e$ was directly measured, and also the thermal conductivity coefficient $k$. Specific thermal capacity $c_{p}$, thermal diffusion $\alpha$ and thermal resistance $R$ were calculated by relationships (2), (3) and (4):

$c_{p}=\frac{e^{2}}{k \cdot \rho}$

$\alpha=\frac{k}{\rho \cdot c_{p}}$,

$R=\frac{\sqrt{4 \cdot \alpha \cdot t}}{k}$

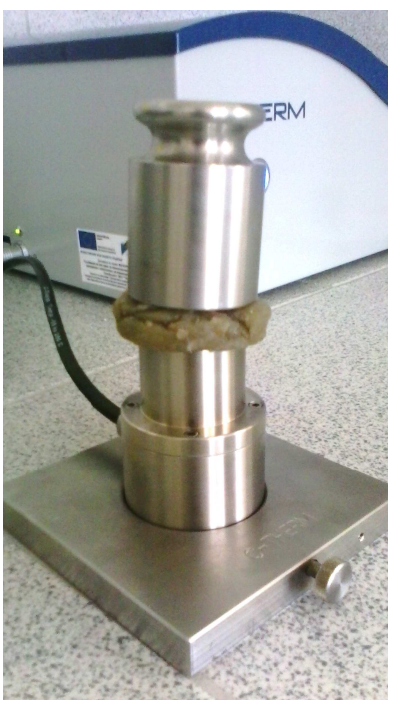

a

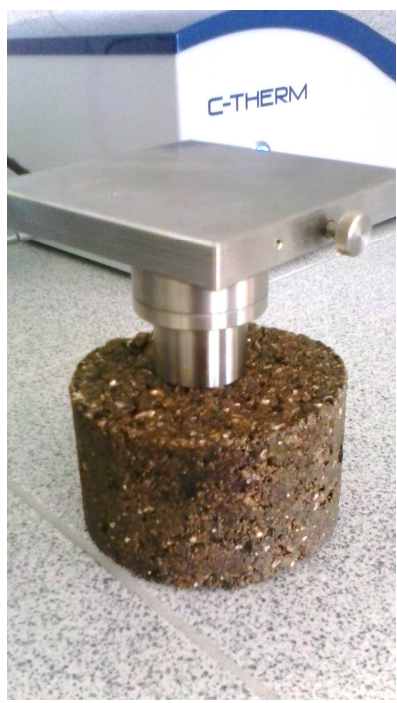

b

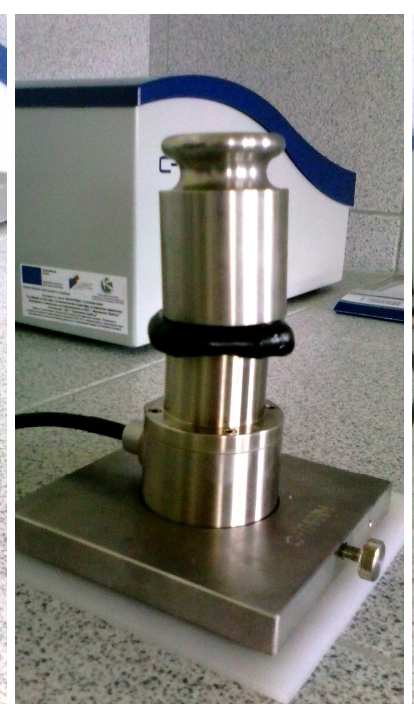

C

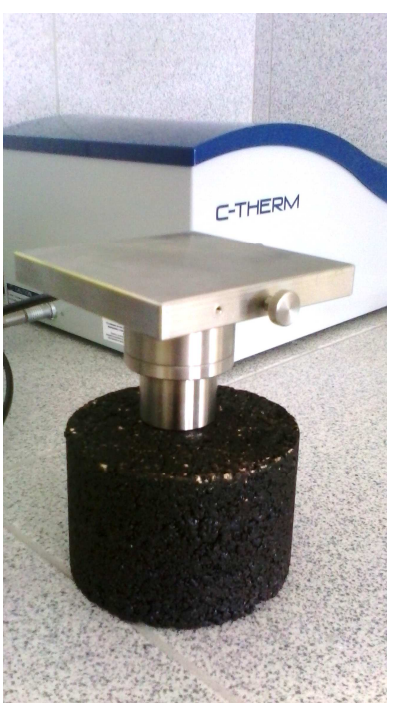

d

Fig. 4: Testing the specimens with the TCi analyzer: a) sample 1; b) sample 2; c) sample 3; d) sample 4.

All tests were carried out in compliance with the TCi analyzer operational methodology, as well as with the requirements of the БДС ISO 22007-2:2015 standard [20]. Before each measurement, a test was conducted with the appropriate calibration material. 


\section{Results and analysis}

The results from the tests are presented in Table 3. The relative standard deviation (RSD) for all tests is less than $5 \%$. There is a good correlation with the results presented by other authors and listed in Table 1.

Table 3: Results from the testing with the TCi analyzer.

\begin{tabular}{|c|c|c|c|c|c|c|}
\hline Study material & $\mathrm{Ws}^{1 / 2} / \mathrm{m}^{2} \mathrm{~K}$ & $\begin{array}{c}k \\
W / \mathbf{m} / K\end{array}$ & $\underset{\mathrm{J} / \mathrm{kg} \cdot \mathrm{K}}{C p}$ & $\begin{array}{c}\rho \cdot C p \cdot 10^{6} \\
\mathrm{~J} / \mathrm{m}^{3} \cdot \mathrm{K}\end{array}$ & $\underset{\mathrm{m}^{2} / \mathrm{s}}{\alpha,}$ & $\begin{array}{c}R, \\
\mathbf{m}^{2} \mathrm{~K} / \mathrm{W}\end{array}$ \\
\hline $\begin{array}{l}\text { Synthetic thermoplastic acrylate } \\
\text { polymer (sample 1) }\end{array}$ & 676.1 & $\begin{array}{c}0.315 \\
\text { (RSD } 0.53 \%)\end{array}$ & 1467.7 & 1.45 & $2.166 \cdot 10^{-7}$ & $2.958 \cdot 10^{-3}$ \\
\hline $\begin{array}{l}\text { Dense asphalt concrete with a } \\
\text { thermoplastic acrylate polymer } \\
\text { (sample 2) }\end{array}$ & 1566.2 & $\begin{array}{c}1.296 \\
\text { (RSD } 3.07 \%)\end{array}$ & 835.8 & 1.91 & $6.844 \cdot 10^{-7}$ & $1.278 \cdot 10^{-3}$ \\
\hline $\begin{array}{l}\text { Viscous petroleum bitumen } \\
\text { (sample 3) }\end{array}$ & 519.9 & $\begin{array}{c}0.179 \\
\text { (RSD } 0.86 \%)\end{array}$ & 1605.3 & 1.50 & $1.188 \cdot 10^{-7}$ & $3.848 \cdot 10^{-3}$ \\
\hline $\begin{array}{l}\text { Dense asphalt concrete with a } \\
\text { viscous petroleum bitumen } \\
\text { (sample 4) }\end{array}$ & 1663.1 & $\begin{array}{c}1.430 \\
(\operatorname{RSD} 1.18 \%)\end{array}$ & 872.0 & 1.93 & $7.398 \cdot 10^{-7}$ & $1.20 \cdot 10^{-3}$ \\
\hline
\end{tabular}

The synthetic acrylic polymer (sample 1), which could be used as a bitumen substitute, showed a higher thermal conductivity than the petroleum viscous bitumen (sample 3), a better propensity to heat exchange with the environment, i.e. a higher value of thermal effusion $e$, as well as a higher sensitivity to temperature changes, i.e. a lower value of specific heat capacity $c_{p}$. The analysis of the values of thermal diffusion $\alpha$ indicates that sample 1 would be more adaptable to temperature changes in the environment since its thermal diffusion value is greater than that of sample 3 . Accordingly [8], it should be expected that less thermal stress will occur with the use of synthetic acrylic polymer than with petroleum viscous bitumen.

The results of the asphalt-concrete tests show that sample 2 has better thermal properties than sample 4. The asphalt-concrete with synthetic acrylic polymer has a lower thermal conductivity coefficient and lower thermal effusion. In terms of sensitivity to temperature changes, both asphalt concretes have similar behavior, i.e. very close values of the specific heat capacity $c_{p}$ and of $\rho . c_{p}$. The analysis of the thermal diffusion values indicates that sample 4 would be more adaptable to temperature changes in the environment since its thermal diffusion value is greater than that of sample 2. Accordingly [8], it should be expected that less thermal stress will be generated when using asphalt-concrete with viscous petroleum bitumen than when using asphalt-concrete with a synthetic acrylic polymer.

\section{Conclusions}

The conclusion that can be drawn based on the results thus obtained and their analysis is that the synthetic acrylic polymer, which is a bitumen substitute, has a higher thermal conductivity than the petroleum viscous bitumen and better adaptability to the temperature changes in the environment. The asphalt-concrete with synthetic acrylic polymer has a lower coefficient of thermal conductivity than asphalt-concrete based on petroleum bitumen, but the two asphalt-concretes have similar sensitivity to temperature changes, i.e. very close values of their specific heat capacity $c_{p}$.

\section{References}

[1] BAI, B. - PARK, D. W. - VO, H. - DESSOUKY, S. - IM, J.: Thermal Properties of Asphalt Mixtures Modified with Conductive Fillers. Journal of Nanomaterials, Vol. 2015, Article ID 926809, 2015, https://doi.org/10.1155/2015/926809.

[2] MOUKOMEL, A. - MORIDPOUR, S.: Relationship between Asphalt Composition and Thermal Behaviour for Solar Energy Collection. Journal of Traffic and Logistics Engineering, Vol. 2, 2014, pp. 230 - 235, https://doi.org/10.12720/jtle.2.3.230-235. 
[3] POLACCO, G. - FILIPPI, S. - MERUSI, F. - STASTNA, G.: A review of the fundamentals of polymer-modified asphalts: Asphalt/polymer interactions and principles of compatibility. Advances in Colloid and Interface Science, Vol. 224, 2015, pp. 72 - 112, https://doi.org/10.1016/ j.cis.2015.07.010.

[4] YILDIRIM, Y.: Polymer modified asphalt binders. Construction and Building Materials, Vol. 21, 2007, pp. 66 - 72, https://doi.org/10.1016/j.conbuildmat.2005.07.007.

[5] ÇENGEL, Y.: Heat Transfer: A Practical Approach. McGraw-Hill, 2003.

[6] PAN, P. - WU, S. - XIAO, Y. - LIU, G.: A review on hydronic asphalt pavement for energy harvesting and snow melting. Renewable and Sustainable Energy Reviews, Vol. 48, 2015, pp. 624 - 634, https://doi.org/10.1016/j.rser.2015.04.029.

[7] MARASTEANU, M. - LI, X. - CLYNE, T. - VOLLER, V. - TIMM, D. - NEWCOMB, D.: Low Temperature Cracking of Asphalt Concrete Pavements. University of Minnesota, 2004.

[8] YAVUZTURK, C. - KSAIBATI, K.: Assessment of Thermal Stresses in Asphalt Pavements Due to Environmental Conditions. University of Wyoming, 2006.

[9] CHADBOURN, B. - LUOMA, J. - NEWCOMB, D. - VOLLER, V.: Considerations of Hot-Mix Asphalt Thermal Properties during Compaction. Quality Management of Hot-Mix Asphalt, American Society for Testing and Materials, 1996.

[10] Asphalt Pavement Sizing Guide CLPM at IAP, 2003.

[11] LUCA, J. - MRAWIRA, D.: New Measurements of Thermal Properties of Superpave Asphalt Concrete. Journal of Materials in Civil Engineering, Vol. 17, 2005, pp. 72 - 79, https://doi.org/ 10.1061/(ASCE)0899-1561(2005)17:1(72).

[12] MRAWIRA, M. - LUCA, J.: Effect of Aggregate Type, Gradation, and Compaction Level on Thermal Properties of Hot-Mix Asphalts. Canadian Journal of Civil Engineering, Vol. 33, 2006, pp. 1410 - 1414, https://doi.org/10.1139//06-076.

[13] CÔTÉ, J. - GROSJEAN, V. - KONRAD, J.: Thermal Conductivity of Bitumen Concrete. Canadian Journal of Civil Engineering, Vol. 40, 2013, pp. 172 - 180, https://doi.org/10.1139/cjce-2012-0159.

[14] AIREY, G. - WILMOT, J. - GRENFELL, J. - IRVINE, D. - BARKER, I. - EL HARFI, J.: Rheology of polyacrylate binders produced via catalytic chain transfer polymerization as an alternative to bitumen in road pavement materials. European Polymer Journal, Vol. 47, 2011, pp. 1300 - 1314, https://doi.org/ 10.1016/j.eurpolymj.2011.03.002.

[15] ISMAIL, W. - ENDUT, I. - ISHAK, S.: Polyacrylate Modified Binder for Sustainable Asphalt Pavement Performances Using Superpave Mix Design. Applied Mechanics and Materials, Vol. 747, 2015, pp. 238 - 241, https://doi.org/10.4028/www.scientific.net/AMM.747.238.

[16] MATHIS, N. - CHANDLER, C.: Direct thermal conductivity measurement technique. US patent US6676287B1, August 7, 2002.

[17] GUSTAFSSON, S. E.: Transient plane source techniques for thermal conductivity and thermal diffusivity measurements of solid materials. Review of Scientific Instruments Vol. 62, 1991, pp. 797 - 804, http://dx.doi.org/10.1063/1.1142087.

[18] KUVANDYKOVA, D.: A New Transient Method to Measure Thermal Conductivity of Asphalt, C-Therm Technologies, 2010

[19] ZLATEVA, P. - PETKOVA-SLIPETS, R.: Comparative analysis of the thermal conductivity coefficient of environmentally friendly building materials. Acta Technica Corviniensis - Bulletin of Engineering, VIII, 2015, pp. 25 - 28.

[20] БДС ISO 22007-2:2015 Plastics - Determination of thermal conductivity and thermal diffusivity Part 2: Transient plane heat source (hot disc) method (ISO 22007-2:2015). 